\title{
PROTOTYPING MODEL UNTUK SISTEM ARCHIEVING PT. HOME CREDIT NDONESIA
}

\author{
Ratna Dewi Yulianti \\ Sistem Informasi \\ STMIK Nusa Mandiri Jakarta \\ Jakarta, Indonesia \\ ratnadewiyulianti@gmail.com
}

\author{
Dewi Ayu Nur Wulandari \\ Komputerisasi Akuntansi \\ AMIK BSI Karawang \\ Karawang, Indonesia \\ dewi.dan@bsi.ac.id
}

\begin{abstract}
Abstrak- Kebutuhan konsumen untuk melakukan transaksi peminjaman dana untuk pembelian barang-barang rumah tangga maupun gadget menggunakan jasa pembiayaan semakin banyak. Untuk PT HOME CREDIT INDONESIA harus memiliki sistem yang canggih untuk merekam data customer nya. Salah satu sistem yang di gunakan di PT ini yaitu sistem Homer untuk menginput nomor kontrak customer . Setelah penginputan di sistem Homer lalu dilanjutkan ke sistem Archiving untuk perekaman penyimpanan nya, tujuan nya adalah untuk memudahkan ketika pencarian saat data tersebut diperlukan. Untuk memudahkan proses keduanya maka perlu adanya penggabungan dua sistem tersebut menjadi satu agar memudahkan, dan menjadikan sistem lebih canggih dan efisien karena tidak dapat menghemat waktu dan tenaga. Dengan penggabungan antara system Homer dan Archiving kebutuhan akan konfigurasi jaringan akan semakin User friendly tanpa meninggalkan system yang lama. Berdasarkan monitoring yang dihasilkan, konfigurasi system Homer dan archiving yang penulis lakukan telah memenuhi kebutuhan yang ada pada PT. Home Credit Indonesia.
\end{abstract}

Keywords : sistem archieving, arsip, arsip online

\section{PENDAHULUAN}

Perusahaan-perusahaan yang ada saat ini harus memiliki keungulan dalam menjalankan proses arsip elektronik, oleh karena itu saat ini banyak perusahaan yang mulai memanfaatkan sistem dan teknologi informasi sebagai alat untuk melakukan arsip data secara elektronik. PT. Home Credit Indonesia merupakan salah satu perusahaan yang sudah menggunakan sistem received dan archiving namun proses recording dokumennya sangat lemah dan berpotensi akan adanya dokumen yang tidak terarsip atau tidak termonitor .

Arsip adalah setiap catatan yang tertulis, tercetak, yang mempunyai arti penting untuk suatu organisasi sebagai bahan komunikasi dan informasi yang terekam pada kertas, kertas film, media komputer, dan lain-lain yang disimpan secara sistematis agar setiap kali diperlukan dapat ditemukan secara cepat dan tepat.

Arsip adalah suatu kumpulan (record/warkat) yang disimpan secara sistematis karena mempunyai suatu kegunaan agar setiap kali diperlukan dapat secara cepat ditemukan kembali (Pancaningsih, 2016)

Keberadaan arsip bagi suatu organisasi tidak sekedar menjadi bukti sejarah, tetapi me- miliki berbagai fungsi dan nilai guna. Secara fungsional, suatu arsip akan dibutuhkan oleh pimpinan untuk bahan pertimbangan dalam mengambil keputusan organisasi. Arsip juga diperlukan sebagai bahan acauan dalam menyusun perencanaan organisasi. Selain itu, arsip juga banyak dipergunakan mendukung kegiatan operasional organisasi. Guna kepentingan pengawasan, arsip menjadi salah satu unsur penting dalam pengendalian organisasi (Sutirman, Wijayanti, \& Purwanto, 2016)

Pada dasarnya arsip elektronik (electronic record) merupakan catatan yang dibuat atau disimpan dalam bentuk elektronik, baik analog atau digital. Arsip elektronik menurut NARA (National Archives and Record Administration) adalah arsiparsip yang disimpan dan diolah dalam suatu format dimana hanya mesin komputer yang dapat memprosesnya. Oleh karena itu arsip elektronik seringkali dikatakan sebagai machine readable records (arsip yang hanya bisa dibaca melalui mesin). Record elektronik merupakan informasi yang terkandung dalam file dan media elektronik, yang dibuat, diterima, atau dikelola oleh organisasi maupun perorangan dan menyimpannya sebagai bukti kegiatan (Rifauddin, 2016).

Sistem informasi efiling dokumen desa merupakan kumpulan dari software dan hardware komputer serta perangkat manusia yang akan mengolah data kearsipan desa yang berupa penyusunan dokumen secara sistematis sehingga bilamana diperlukan lagi dapat ditemukan kembali secara cepat yang akan dibutuhkan desa Bangun. Pengarsipan desa bangun masih manual dan tata 
letaknya yang sulit diingat dalam jangka panjang saat dibutuhkan (Wati, Ratna, \& Astutik, 2017).

Tujuan penelitian ini adalah untuk membuat sistem Archiving berbasis Dekstop pada PT. Home Credit Indonesia dengan tujuan untuk mengembangkan sistem yang ada dimana didalam sistem yang lama proses pendataan berjalan lama dan seringnya terjadi kesalahan dan dokumen yang tidak terarsip ke dalam

\section{KAJIAN LITERATUR}

A. Arsip

Kata arsip dalam bahasa Latin disebut felum (bundle) yang artinya tali atau benang. Dan memang pada zaman dahulu tali atau benang ini digunakan untuk mengikat kumpulan warkat/surat. Sehingga arsiparsip itu mudah digunakan (Pancaningsih, 2016)

B. Informasi

informasi merupakan data yang telah diklasifikasikan atau diolah atau diinterpretasikan untuk digunakan dalam proses pengambilan keputusan (Hamim, 2014).

\section{Sistem}

Sistem adalah rangkaian dari dua atau lebih komponen-komponen yang saling berhubungan, yang berinteraksi untuk mencapai suatu tujuan.Sebagian besar sistem terdiridari subsistem yang lebih kecil yang mendukung sistem yang lebih besar (Romney \& Steinbart, 2015)

\section{Sistem Informasi}

Perancangan atau perancangan sistem adalah tahapan perantara untuk memetakan spesifikasi atau kebutuhan sistem yang akan dibangun ke Perancangan pemodelan agar lebih mudah diimplementasikan dengan pemrograman (Sukamto \& Salahudin, 2013.)

Sistem informasi adalah "sebuah rangkaian prosedur formal dimana data dikelompokkan, diproses menjadi informasi, dan didistribusikan kepada pemakai" (Kadir, 2014)
E. UML (Unified Modeling Language)

Merupakan standar bahasa yang digunakan di dunia industri untuk mendefinisikan requiretment, membuat analisis dan Perancangan, serta menggambarkan arsitektur dalam pemrograman berorientasi objek (Sukamto \& Salahudin, 2013.)

\section{F. Database}

Basis data atau (database) adalah suatu pengorganisasian sekumpulan data yang saling terkait sehingga memudahkan aktivitas untuk memperoleh informasi(Kadir, 2014).

\section{METODOLOGI}

\section{A. Metodologi Penelitian}

Metode Penelitian yang penulis gunakan adalah metode Research and Development (R\&D). Menurut Borg and Gall dalam Sugiyono, menyatakan bahwa penelitian dan pengembangan Research and development (R\&D), merupakan metode penelitian yang digunakan untuk mengembangkan atau memvalidasi produk-produk yang digunakan dalam pendidikan dan pembelajaran. Sedangkan menurut Sugiyono mengatakan bahwa metode penelitian dan pengembangan atau dalam bahasa Inggrisnya Research and Development adalah metode penelitian yang digunakan untuk menghasilkan produk tertentu, dan menguji keefektifan produk tersebut (Sugiyono, 2014).

Ada beberapa langkah yang harus dilakukan dalam penggunaan metode Research and Development menurut Sugiyono tersebut adalah sebagai berikut : (Sugiyono, 2014)

Sumber : (Sugiyono, 2014)

\section{Gambar 1. Tahapan Metode Reserach and Development}

Tahapan metode Research and Development adalah sebagai berikut :

a. Potensi dan Masalah

Potensi merupakan segala sesuatu yang apabila diberdayakan akan memiliki nilai tambah. Masalah juga dapat merupakan sebagai sumber potensi. Masalah yang ada apabila diteliti dapat 


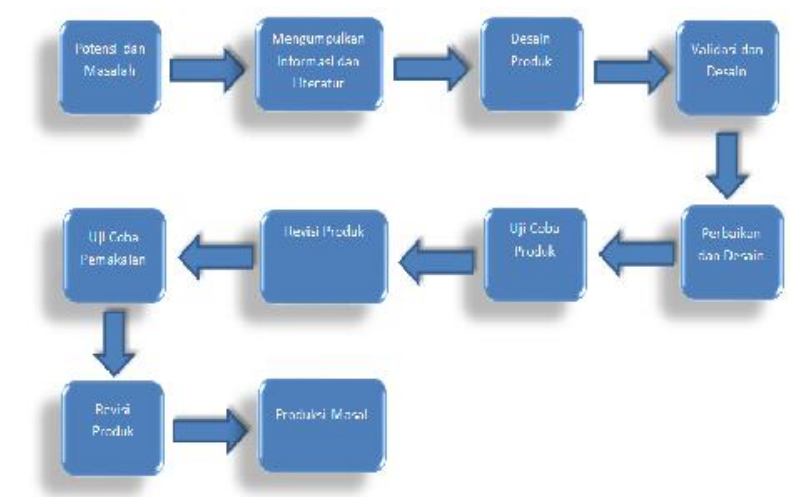

di atasi dengan membuat sebuah model sebagai solusi dari penyelesaian masalah.

b. Mengumpulkan Informasi dan Literatur

Tahapan ini dilakukan untuk menemukan konsep dan landasan teoritis tentang masalah yang di bahas. Pada tahapan ini dibahas ruang lingkup suatu produk, keluasaan penggunaan, kondisi pendukung, dll. langkah-langkah yang tepat untuk mengembangkan produk, memberikan gambaran hasil penelitian terdahulu sebagai bahan perbandingan untuk mengembangkan

c. Desain Produk

Studi ini ditujukan untuk menemukan konsep-konsep atau landasan-landasan teoretis yang memperkuat suatu, produk. Produk pendidikan, terutama produk yang berbentuk model, program, sistem, pendekatan,software dan sejenisnya memiliki dasar-dasar konsep atau teori tertentu.

d. Validasi Desain

Validasi desain merupakan proses kegiatan untuk menilai apakah rancangan produk, dalam hal ini sistem kerja baru secara rasional akan lebih efektif dari yang lama atau tidak. Dikatakan secara rasional, karena validasi disini masih bersifat penilaian berdasarkan pemikiran rasional, belum fakta lapangan.

e. Perbaikan Desain

Setelah desain produk, divalidasi melalui diskusi dengan pakar dan para ahli lainnya . maka akan dapat diketahui kelemahannya. Kelemahan tersebut selanjutnya dicoba untuk dikurangi dengan cara memperbaiki desain. Yang bertugas memperbaiki desain adalah peneliti yang mau menghasilkan produk tersebut.

\section{B. Metodologi Pengembangan Sistem}

Dalam pengembangan sistem archieving pada PT. Home Credit Indonesia, metode pengembangan sistem yang digunakan adalah prototyping model. Keuntungan yang diperoleh dalam menggunakan metode prototyping adalah mendapatkatkan umpan balik yang cepat dari customer (Rosi Subhiyakto \& Wahyu Utomo, 2017)

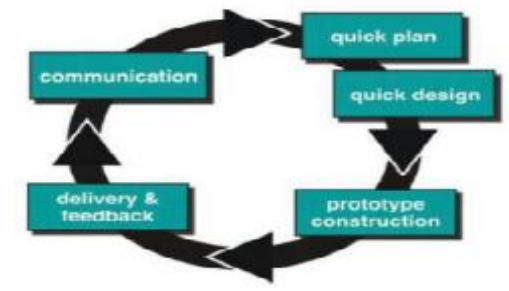

Gambar 2

Tahapan Prototyping Model

Sumber : (Rosi Subhiyakto \& Wahyu Utomo, 2017)

Dalam metode prototyping model, tahap awal adalah tahap perencaaan. Dalam tahapan ini, perencanaan dilakukan dengan cepat. Tahapan selanjutnya adalah tahapan perancangan aplikasi dan dilanjutkan ke tahap pembuatan prototype aplikasi. Setelah prototype aplikasi dibuat, tahap selanjutnya adalah memberikan prototype tersebut kepada pengguna untuk di review dan diberikan umpan balik. Keuntungan menggunakan prototyping model adalah adanya komunikasi yang terjalin dengan intens antara pengguna dan pengembang. Selain itu juga memudahkan analis sistem dalam menentukan kebutuhan pengguna yag sesungguhnya sehingga meminimalkan kesalahan persepsi yang mngkin terjadi dalam membangun sistem.

\section{HASIL DAN PEMBAHASAN}

Berikut ini akan dijelaskan tahapan pengembangan sistem sesuai dengan metode prototyping model

A. Tahap Perencanaan (Analisa Kebutuhan Pengguna)

Berdasarkan hasil analisa kebutuhan pengguna, dan untuk mengatasi permasalahan yang ada, maka sistem yang dibuat akan digunakan oleh bagian administrasi adalah sebagai berikut :

- Admin dapat melakukan login. 
- Admin dapat melakukan monitoring status kontrak.

- Admin dapat menghapus kontrak yang berstatus receive.

- Admin dapat membuat printout sebagai bukti telah melakukan receive kontrak

- Admin tidak dapat memasukan nomor kontrak yang tidak sesuai dengan sistem.

- Admin dapat melakukan scan barcode pada saat receive kontrak.

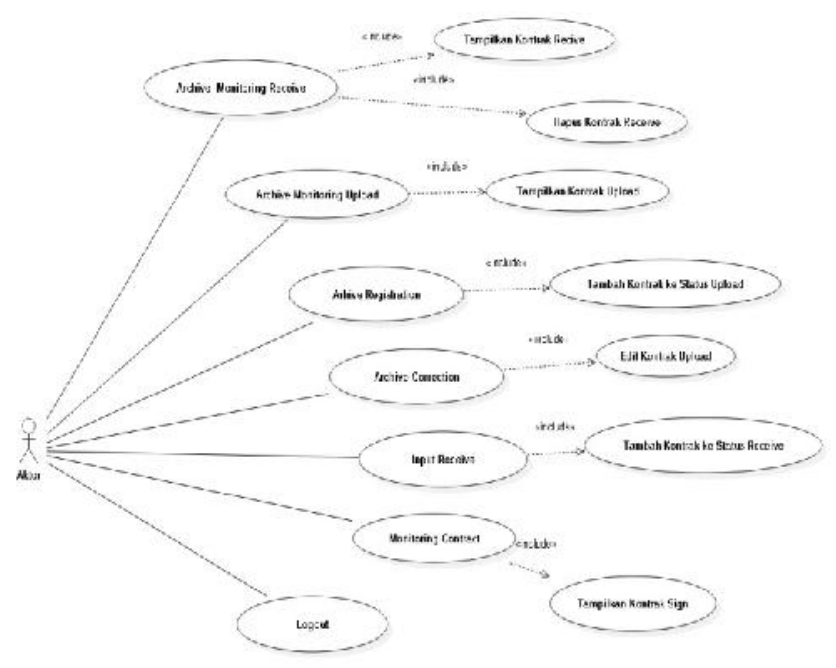

Gambar 3

Use Case Diagram Sistem Archieve PT. Home Credit Indonesia

\section{B. Perancangan (Design)}

Setelah tahap perencanaan selesai, tahap berikutnya adalah tahap perancangan atau desain. Pada tahap desain ini, desain yang akan dilakukan adalah desain database (logical data model dan physical data model), desain form dan desain component diagram dan deployment diagram

\section{Desain database}

Database adalah kumpulan informasi yang disimpan di dalam komputer yang secara sistematik, sehingga dapat diperiksa menggunakan suatau program komputer untuk memperoleh informasi dari database tersebut. Database menggambarkan hubungan antar tabel yang dibuat beserta relasi antar tabel.

Database akan di gambarkan secara logical data model dan physical data model.

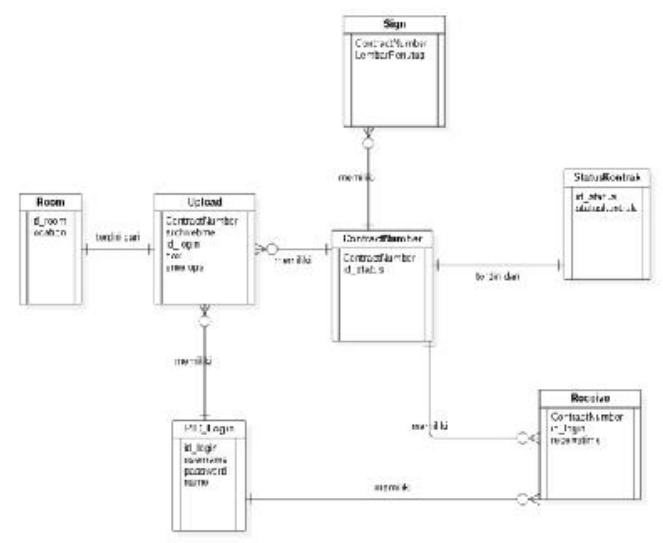

Gambar 4 Logical Data Model Portal Home Credit

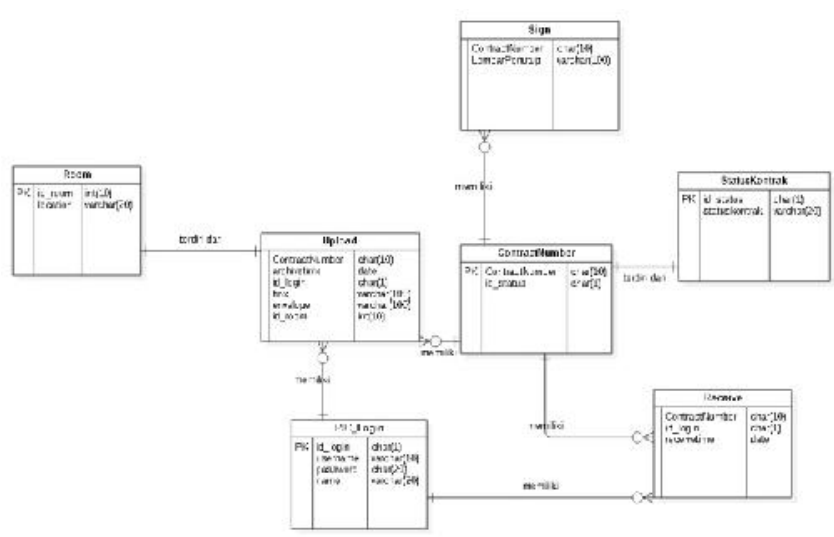

Gambar 5 Physical Data Model Portal Home Credit

2. Desain Form

Form yang akan dibuat disesuaikan dengan kebutuhan sistem archieving pada PT. Home Credit Indonesia. Adapun form yang dibuat antara lain sebagai berikut :

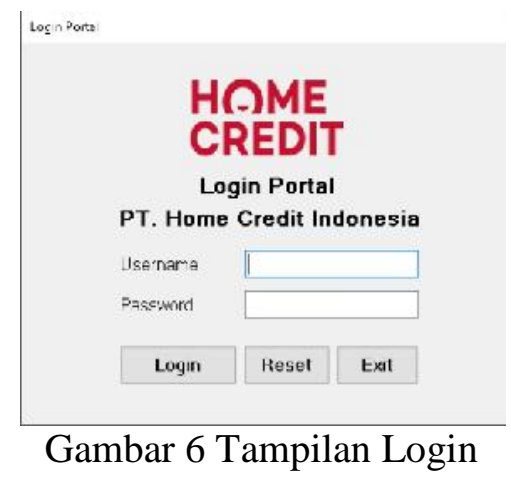


Halaman login digunakan pertama kali oleh user sebelum masuk ke dalam sistem. Hanya user yang mempunyai akses yang dapat masuk ke dalam sistem.

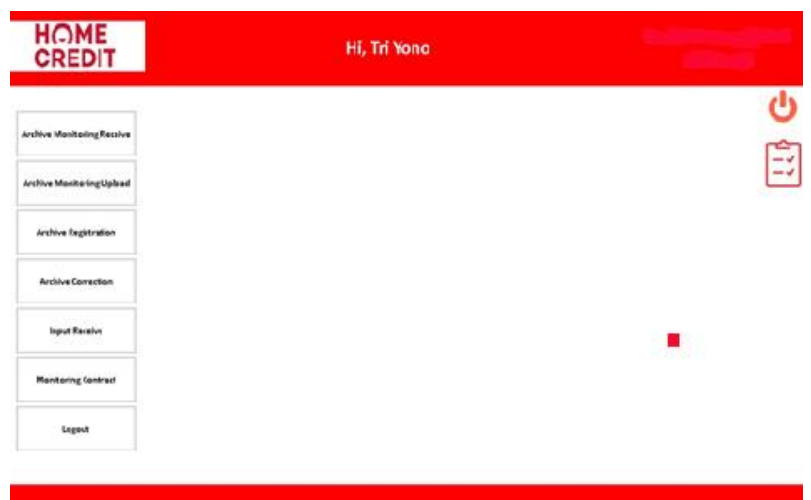

Gambar 7 Tampilan Menu Utama Sistem Archieving PT. Home Credit Indonesia

Setelah user login, maka akan tampil halaman menu utama yang menampilkan menu apa saja yag dapat di akses oleh user.

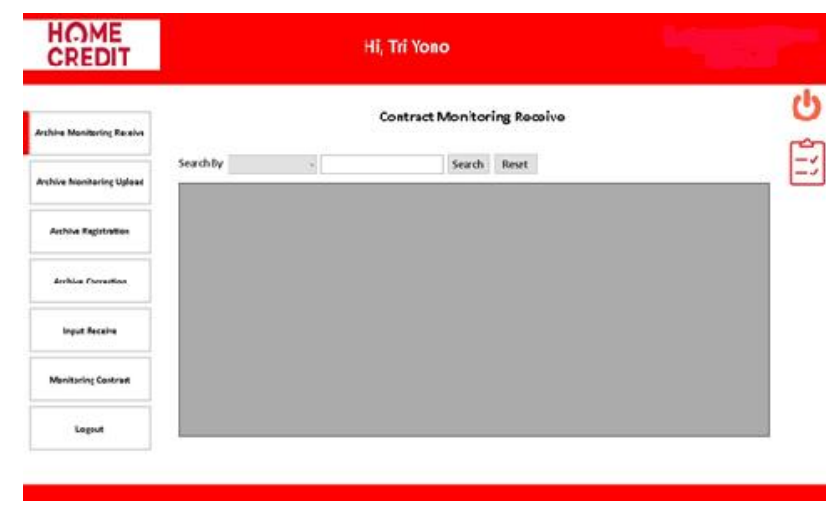

Gambar 8 Tampilan Form Archive Monitoring Receive Sistem Archieving PT. Home Credit Indonesia

Gambar 8 merupakan tampilan untuk user memonitoring kontrak yang diterima.

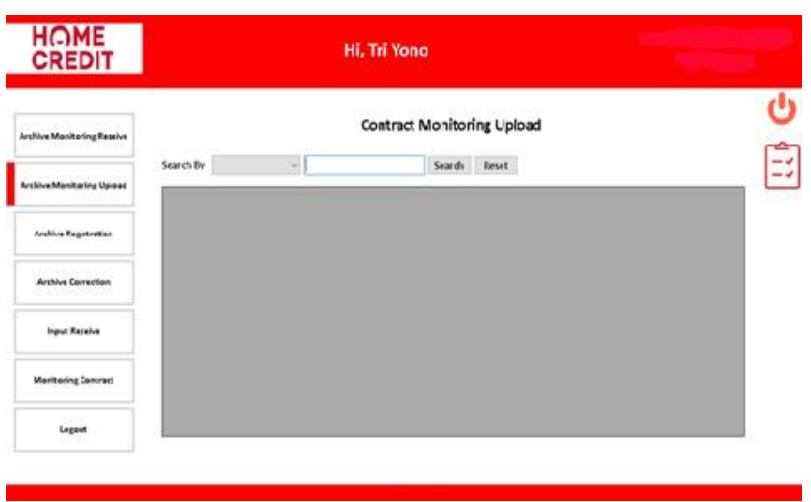

Gambar 9 Tampilan Form Archive Monitoring Upload Sistem Archieving PT. Home Credit Indonesia

Gambar 9 merupakan tampilan user pada saat akan meng-upload berkas kontrak yang disetujui

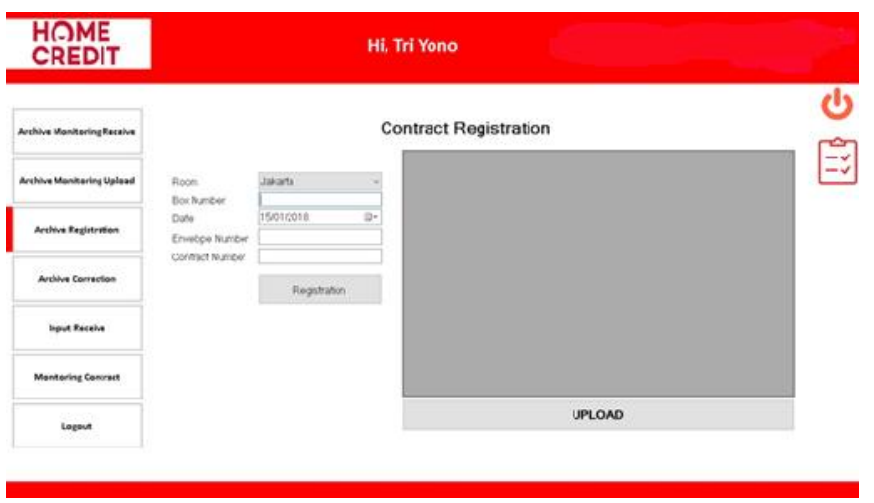

Gambar 10 Tampilan Form Registration Contract Sistem Archieving PT. Home Credit Indonesia

Gambar 10 merupakan tampilan saat user mendaftarkan kontrak baru untuk masuk ke proses selanjutnya

3. Desain Component Diagram dan Deployment Diagram

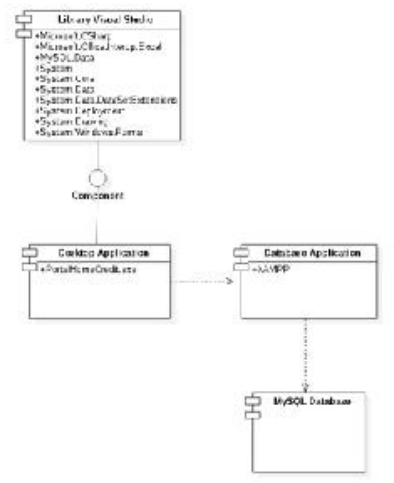

Gambar 11. Component Diagram Sistem Archieving PT. Home Credit Indonesia 


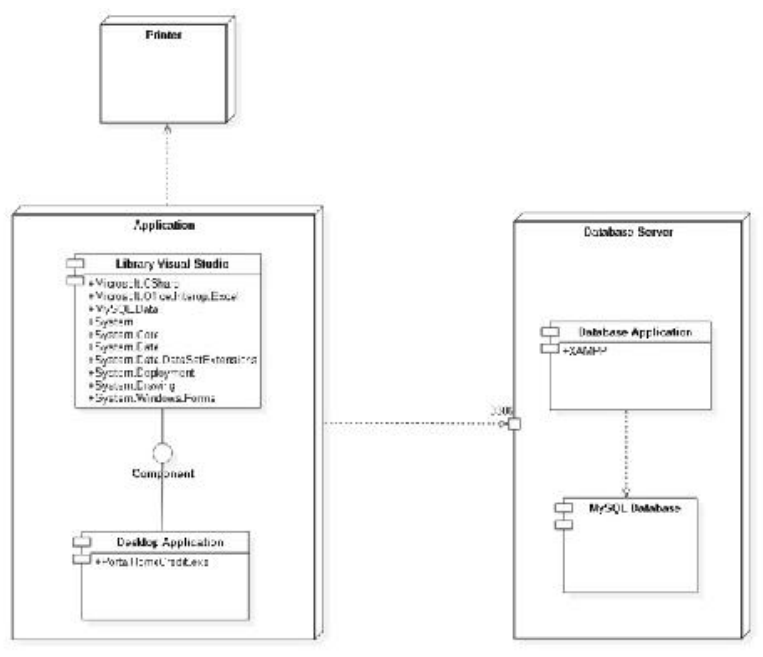

Gambar 12. Deployment Diagram Sistem Archieving PT. Home Credit Indonesia

\section{KESIMPULAN}

Setelah melewati tahapan analisis, perancangan dan implementasi aplikasi sistem Archiving pada Back office di PT. Home Credit Indonesia ini, maka penulis mendapatkan beberapa kesimpulan diantaranya adalah sebagai berikut:

1. Penggabungan antara sistem Receiving dan Archiving menjadi satu sistem akan memudahkan setiap operator, sehingga dapat menghemat waktu ..

2. Sistem ini mengurangi kesalahan manusia (human eror) dalam proses pengolahan data operator.

3. Sistem ini sudah dapat membaca kesalahan ketika scan barcode yang masuk bukanlah nomor kontrak yang dituju.

4. Kemudahan mencari dokumen kontrak yang ketika diperlukan sehingga dapat menyampaikan informasi dengan cepat dan tepat .

\section{REFERENCES}

Hamim, T. (2014). Analisis Serta Perancangan Sistem Informasi Melalui. Pendekatan UML. Yogyakarta: Andi offset.

Kadir, A. (2014). Pengenalan Sistem Informasi. Yogyakarta: Andi.

Pancaningsih, R. S. (2016). Manajemen Kearsipan. Orbith, 12(3), 120-125.

Rifauddin, M. (2016). Pengelolaan Arsip Elektronik Berbasis Teknologi. Khizanah Al-Hikmah, 4(2), https://doi.org/10.24252/kah.v4i27

Romney, M. B., \& Steinbart, P. J. (2015). Sistem Informasi Akuntansi. Jakarta: Salemba Empat.

Rosi Subhiyakto, E., \& Wahyu Utomo, D. (2017). ANALISIS DAN PERANCANGAN APLIKASI PEMODELAN KEBUTUHAN PERANGKAT LUNAK MENGGUNAKAN METODE PROTOTYPING. Retrieved from https://media.neliti.com/media/publications/17 4414-ID-analisis-dan-perancangan-aplikasipemode.pdf

Sugiyono. (2014). Metode Penelitian Pendidikan Pendekatan Kuantitatif, Kualitatif, dan $R \& D$. Bandung: Alfabetha.

Sukamto, R. A., \& Salahudin. (n.d.). Rekayasa Perangkat Lunak. Bandung: Informatika.

Sutirman, Wijayanti, N. S., \& Purwanto. (2016). Studi Tentang Implementasi Sistem Manajemen Arsip Elektronik Pada Kantor Pemerintahan Kota Yogyakarta. EfisiensiKajian Ilmu Administrasi, XIV(1), 70-79.

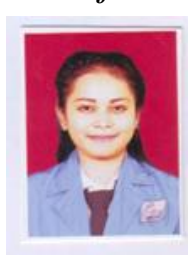
Wati, Y. K., Ratna, I., \& Astutik, I. (2017). Sistem Informasi Efiling Dokumen Desa Berbasis Web Studi Kasus Desa Bangun-Pungging, 8 .

AUTHORS PROFILE

Ratna Dewi Yulianti. Tahun 2018 lulus dari Program Studi Sistem Informasi (S1) STMIK Nusa Mandiri Jakarta. 


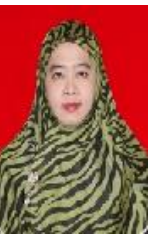

Dewi Ayu Nur Wulandari. Tahun 2005 lulus dari Program Studi Sistem Informasi (S1) STMIK Nusa Mandiri Jakarta. Tahun 2010 lulus dari Program Strata Dua (S2) program Studi Ilmu

Komputer STMIK Nusa Mandiri Jakarta. Tahun 2013 sudah tersertifikasi dosen dengan Jabatan Fungsional Lektor di AMIK BSI Karawang. 